\title{
Tourism Clusters, Characteristics, Principles and Developing Theory
}

Xhevahir DOÇAJ

Shpresim DOMI

Arben TERPOLLARI

Edmond KADIU

Faculty of Economy \& Agribusiness, Agricultural University Of Tirana

\section{Abstract}

This is a descriptive paper that intends to analyze the Tourism Cluster Theory, considering the theoretical consideration, different opinions and ways of approaches. It considers carefully definitions, and the essential basic factors and characteristics that determine conditions and chances of creating a tourism cluster system. Importance of the competition and possible cooperation meantime between present actors in a specific location. Very significant aspects and elements of the cluster areas follows: technology, innovation and creative innovative ideas, marketing, operating mode; significance of suppliers evaluating meantime its influence on the added value chain of local Agri-tourism development. Clusters as well can create economy of scales and bring profits to the cluster's actors. Furthermore, concept of the sustainable tourism is a keyword of developing policies, what makes present active subjects to think globally.

\section{Keywords}

Tourism, cluster, competition, cooperation, sustainable development

\section{Introduction}

\section{Literature Review}

Tourism is a sector that favours local development because it generates jobs, increases the income of workers and stimulates capital investments through new business opportunities, which results in the establishment of new organizations, including SME, among other advantages (WTO, 2004).

Clusters are geographic concentrations of interconnected companies and institutions in a particular field. Clusters encompass an array of linked industries and other entities important to competition. They include, for example, suppliers of specialized a- inputs such as components, machinery, and services, and providers of specialized infrastructure. Clusters also often extend downstream to channels and customers and laterally to manufacturers of complementary products and to companies in industries related by skills, technologies, or common inputs. Finally, many clusters include governmental and other institutions- such as universities, standards-setting agencies, think tanks, vocational training providers, and trade associations-that provide specialized training, education, information, research, and technical support(Porter, 1998).

The tourism cluster is a group of highlighted tourist attractions within a limited geographic area equipped with high quality equipment and services, social and political cohesion, linkages between productive chains and accompanying culture, and excellent management in companies' networks that bring comparative and competitive strategic advantages, (Beni, 2003).

Clusters are used to represent concentrations of companies so that they can produce synergy through their geographical proximity and interdependence (Rosenfeld, 1997).

A Cluster in Tourism is linked to a tourist product and a tourist destination. Kosta (2005) adds that the development of the cluster in tourism should include the following components:

Static elements represented by accommodation and restoration;

Mobile data elements for passenger services, tourist agencies and operators, rent-a-car service; 
Dynamic, recreational, cultural and sporting elements are largely responsible for increasing consumption.

Clusters show an intern configuration that generally includes:

a set of tourist attractions that draw non-resident attention;

the concentration of tourism service companies: restaurants, accommodation, transport services, crafts, travel agencies etc.;

sectors providing support to tourism services;

suitable and low-cost infrastructure (roads, energy, sanitation, health services, etc.);

companies and institutions that provide specialized qualification, information and financial capital;

intern agents organized into class associations;

government agencies and other regulating bodies that impact tourism agglomerations.

\section{Characteristics of Clusters}

Some of the cluster characteristics follow the following:

are a limited form of regional economic activity within the related sectors, usually associated with some scientific institutions (universities, researches and innovations, etc.);

represent the links (chain of value) that create vertical and narrow specific zones in which the common (interconnected) stages of the manufacturing process are the main group (eg, the "supplier - manufacturer - merchant - consumer" chain). This category includes firms around the main (dominant) networks;

industries are placed at a high level of collection (eg airline collection) or sectors of compliance still at a collection level (eg agro-touristic grouping).

information exchange between companies, institutions and individuals who are part of the cluster,

the existence of a diversity of institutional infrastructure to support activities, socio-cultural identity,

collective competitive advantages,

the implementation of strategic actions among agents and the simultaneous organization of competition and cooperation relations among agents.

\section{Integrations in a Cluster}

The relations between enterprises and institutions and a tourism cluster can be understood in two ways (Rodrigues, 2001):

Horizontal - by the creation of strategic alliances, where agreements can be of two kinds: on one side, the agreements between enterprises that have the same principal activity, i.e. among enterprises that deal with lodging, entertainment, transport and catering. On the other side, the agreements between enterprises working with the same group of customer satisfaction, but offering different product components to the customers (tourism service);

Vertical - by the creation of strategic nets, where there is the establishment of a unilateral supplier customer relation among the partners in such a way that the object activities of the agreement are fulfilled by one of the parts, which gives its output to the other in exchange for a payment(Cunha, 2005). 


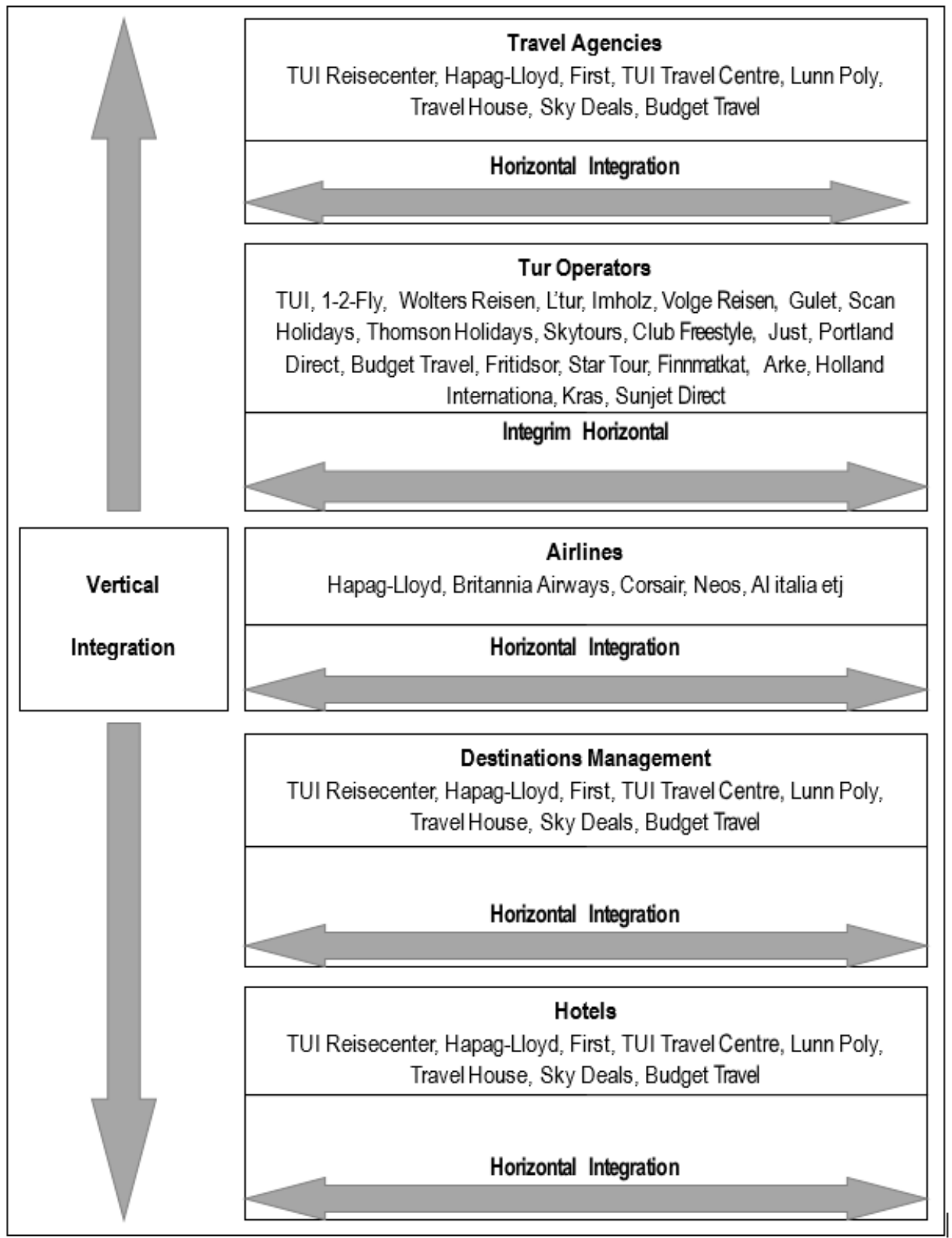

Integrations of Tourism Business

\section{Competitive Advantages of Clusters}

Porter (1990) noted that competitive advantage is sustained only through relentless improvements to the firm's product and organisation. Geographical concentration, indeed, is important for organisational improvement and technological innovation 
(Baptista and Swann, 1999). Concentration and accumulation of knowledge in the cluster will attract increased human capital to the cluster and, since the information exchange tends to be more informal, the spread of knowledge outside the region becomes limited. Baptista (1996) suggested that technological innovation is the heart of the dynamic process of cluster growth, accessed by new firm entry and incumbents' growth. Arthur (1990) noted that strong clusters tend to attract more firms, and regions with strong innovative record have an advantage in achieving more innovation; they are selffulfilling and path-dependent. Innovative activity and output are positively correlated with new firm entry and productivity growth(Kuah, 2002).

Porter (1998) summed up that clusters greatly affect competition and create competitive advantage in three ways:

Increasing the productivity of group-based companies;

Taking care of the direction and pace of innovation, which supports future productivity growth; and

Stimulating the formation of new businesses that expand and strengthen the group, forming a virtuous circle or positive feedback.

Porter (1998) summed up that the groupings have a profound impact on competition and create competitive advantage in three ways:

Increasing the productivity of group-based companies;

Taking care of the direction and pace of innovation, which supports future productivity growth; and

Stimulating the formation of new businesses that expand and strengthen the group, forming a virtuous circle or positive feedback.

Swann's (1998) positive feedback model aptly sums up how the clustering phenomenon, felt through the entry of new firms and the growth of incumbent firms, leads to a positive feedback loop, which will induce further growth within the cluster. The main findings being:

Firms in clusters grow faster than average (if clustered with others in their own sub-sector of the industry);

Clusters attract a disproportionate amount of new entry (but a cluster strong in sub-sector $\mathrm{X}$ will typically attract entry into another sub-sector $Y$ - not into $X$ itself);

Firms in clusters are more innovative (whether we measure this by patent counts or innovation counts);

Firms in clusters that are strong in sub-sectors other than the firm's own do not grow faster - and might sometimes grow slower. The same ambivalence applies to the propensity of firms in clusters to introduce innovations; and,

In biotechnology, the strength of the science base in a cluster had a strong positive effect on new firm formation and growth of firms in that cluster(Kuah, 2002).

\section{Clusters and sustainable development}

Local development considering the principle of sustainable development involves many complex relationships and is possible to be realized at the moment when considering the real size of a given area or territory. Ruschmann (2001) underlined the need to consciously consider the following dimensions when it comes to developing and implementing strategies for sustainable local development:

Ecological and Environmental Sustainability: -is the capacity to endure. In ecology the word describes how biological systems remain diverse and productive over time. For humans it is the potential for long-term maintenance of well being, which in turn depends on the maintenance of the natural world and natural resources.

Economic Sustainability -refers to practices that support long-term economic growth without negatively impacting social, environmental, and cultural aspects of the community.

Socio-cultural sustainability -this is the need to preserve the cultural diversity, values and practices currently existing in a region and the building of individual citizenship and full social integration within a culture that includes rights and duties. 
Political-institutional sustainability-the strengthening of democratic mechanisms aimed at the design and implementation of public policies, institutional arrangements and representative political and social bodies that have already received solid criteria.

\section{Conclusions}

Clusters are those organizations that can create competitive advantages and economies of scale for business companies, and is one of the most important models of economic development based on the competitions, involvement and cooperation of the economic environment, considering the importance of the innovation and research institutions, the educational system, authorities and also the significance of the different tourism organizations.

Clusters, among other things, affect competition in several dimensions: first by increasing the productivity of companies in the area; second, by guiding the direction and pace of innovation, which reinforces productivity growth in the future; third, by stimulating the creation of new businesses, which expand and strengthen the cluster itself.

A cluster is also a form of network that occurs within a geographical location, where the proximity of firms and institutions ensures certain commonality, increases the impact and frequency of communications and interactions.

Associated firms in a tourism cluster can highlight managerial and economic benefits as well as create opportunities for the creation and implementation of strategies to support sustainable tourism development.

A well developed cluster also provides an efficient means of obtaining other important inputs. Such a cluster offers a deep and specialised supplier base. Sourcing locally instead of distant suppliers lowers transactional costs.

\section{Bibliography}

[1] Cunha, S. K. d., 2005. Tourism Cluster Competitiveness and Sustainability: Proposal for a Systemic Model to Measure the Impact of Tourism on Local Development. Brazilian Administration Review, pp. 48-52.

[2] Kuah, A. T., 2002. Cluster Theory and Practice: Advantages for the Small Business Locating in a Vibrant Cluster, Cluster Theory and the Small Business: 206 - 228. Journal of Research in Marketing and Entrepreneurship, IV(3), pp. 206-228.

[3] Porter, M. E., 1998. Clusters and The New Economics of Competitions. Harvard Business School Press.

[4] Kachniewska, Magdalena, Towards the Definition of a Tourism Cluster (March 17, 2014). Journal of entrepreneurship, management and innovation JEMI_2013_Vol_9_Issue_1_art 03 pp. 33-56. Available at SSRN: https://ssrn.com/abstract=2410446.com

[5] Porter, M. E. (1999). Competição. (2nd ed.). Rio de Janeiro: Campus.

[6] Smith, S. (1989). Tourism analysis. A handbook. New York/London: Longman.

[7] Porter, M.E. (1980), Competitive strategy, New York: Free Press.

[8] Porter, M.E. (1985), Competitive advantage, New York: Free Press.

[9] Porter, M.E. (1998b), Location, clusters and the 'new' microeconomics of competition, Business Economics.

[10] https://books.google.al/books?hl=en\&lr=\&id=UB4siUvBSZgC\&oi=fnd\&pg=PR3\&dq =tourism+clusters+in+europe\&ots=\|IVfj58Xb\&sig=OSI4XNbChnJZkz81rkNGD20LwQ\&redir_esc=y\#v=onepa ge\&q=tourism $\% 20$ clusters $\% 20$ in $\%$ 20europe\&f=false

[11] https://journalsuggester.springer.com/

[12] https://www.sciencedirect.com/science/article/pii/S1877042815058668 